\title{
EDITORIAL
}

\section{The transition to adulthood as a critical juncture in the course of psychopathology and mental health}

\author{
JOHN E. SCHULENBERG ${ }^{a}{ }^{\text {ARNOLD J. SAMEROFF, }}{ }^{a}$ \\ AND DANTE CICCHETTI ${ }^{b}$ \\ ${ }^{a}$ University of Michigan; and ${ }^{b}$ Mt. Hope Family Center
}

Few students of psychopathology and mental health would argue that the period between adolescence and adulthood is simply a passive medium through which individuals pass untouched, a segment of the life span that has no unique impact on ongoing trajectories of functioning and adjustment. Yet the relative lack of attention given to this period in theoretical conceptualizations and empirical investigations suggests an assumption that the events and experiences constituting the transition to adulthood are relatively inconsequential to the course of psychopathology and mental health. In comparison, far more attention has been

John Schulenberg's work on this Special Issue was supported, in part, by grants from the National Institute on Mental Health (NIMH, MH59396) and the National Institute on Drug Abuse (NIDA, DA01411), Arnold Sameroff's work was supported by a grant from NIMH (MH59396), and Dante Cicchetti's work was supported by grants from NIDA (DA12903) and the Spunk Fund, Inc. This Special Issue is based, in part, on the Michigan Symposium on Development and Psychopathology: Continuity and Discontinuity during the Transition to Adulthood, held at the University of Michigan in June 2002, chaired by John Schulenberg and Arnold Sameroff, and sponsored by the NIMH-funded Center for Development and Mental Health, the Institute for Social Research, Office of the Vice President for Research, and Center for Human Growth and Development.

Address correspondence and reprint requests to: John Schulenberg, Survey Research Center, Institute for Social Research, University of Michigan, Ann Arbor, MI 48106-1248. given to childhood effects on adult psychopathology. Early experiences may be critical, and deserve all the attention they are given; however, their influences on later psychopathology and mental health are likely mediated and sometimes reversed by later experiences (Cicchetti \& Tucker, 1994; Curtis \& Cicchetti, 2003; Sroufe, 1997; Sroufe, Carlson, Levy, \& Egeland, 1999; Sroufe, Egeland, \& Kreutzer, 1990). There is a clear need to devote equal attention to more developmentally proximal influences (Cairns, 2000; Lewis, 1999; Schulenberg, Maggs, \& O’Malley, 2003). This is especially true from a systems perspective, where development is viewed as a function of strong person-context interactions with a temporal course given to fits and starts that correspond, at least in part, to shifts in the individual, the context, and the interaction between the two (Cicchetti \& Rogosch, 2002; Sameroff, 2000). More specifically, developmental transitions, representing major life changes within individuals and in social roles and contexts, can contribute to alterations in the course of mental health and psychopathology.

The transition from adolescence to adulthood is one of the most critical of normative life transitions because it typically involves pervasive and often simultaneous contextual and social role changes. However, the question remains as to whether this transition is equally powerful in influencing the course of 
psychopathology and mental health. To what extent does this global transition (and all of the various developmental transitions embedded within it) contribute to continuity and discontinuity in psychopathology and mental health? This is the primary question addressed by the papers in the Special Issue. Based on extant empirical evidence, continuity prevails for most individuals during the transition when one's accumulated talents, support, and hopes interact with the new opportunities and challenges of life after high school (Schulenberg $\&$ Zarrett, in press). The trajectories of functioning and adjustment established throughout childhood and adolescence likely carry into early adulthood and work together with (or against) the pervasive changes in roles and settings that may accompany this transition, yielding continuity in overall functioning and adjustment into adulthood. Similarly, the stressors of the transition can contribute to the manifestation or consolidation of psychopathology that was subthreshold during adolescence.

In many ways, however, groups of "off diagonals" representing discontinuity in psychopathology and mental health are the most interesting in terms of understanding the power of this developmental transition (Schulenberg et al., 2003). Some troubled and troubling adolescents turn their lives around and become well-functioning young adults. However, for studies of developmental psychopathology, those individuals who do well as adolescents, but then fall apart during the transition, are of equal interest. These disparate scenarios give rise to important questions: (a) to what extent are these discontinuities rooted in earlier experiences and, thus, in part, predictable in advance? (b) to what extent do the discontinuities emerge out of transitional experiences themselves? and (c) to what extent are these discontinuities (for better or worse) reflective of just a momentary perturbation or of a real change in developmental course reflecting a turning point? The answers to these questions require a clear understanding of the mechanisms of person-context interactions.

By considering these and other key questions, this Special Issue of Development and Psychopathology is devoted to providing a better understanding of the transition to adult- hood and how it may influence the course of psychopathology and mental health. Our goal is to direct more attention to this specific major life transition, and, more generally, to highlight the importance of major developmental transitions across the life span of psychopathology. We set the stage in this introduction by providing a brief overview of the transition to adulthood, of continuity and discontinuity across developmental transitions, and of the themes addressed by the authors of the articles included in this Special Issue.

\section{The Transition to Adulthood}

The period between adolescence and adulthood is marked by increased diversity in life paths and timing of developmental milestones (e.g., Cohen, Kasen, Chen, Hartmark, \& Gordon, 2003; Schulenberg, O'Malley, Bachman, \& Johnston, in press; Sherrod, Haggerty, \& Featherman, 1993). This increased diversity is due, in part, to the expression of existing trajectories that may have been restrained during adolescence (e.g., due to the relative homogeneity of secondary school student roles), as well as to the creation of new paths as a function of opportunities and experiences during the transition. For many, flexibility and self-direction in day-to-day life increases, and geographic mobility is greater in this period than in any other period of life (Shanahan, 2000). In the past few decades, this transition period has lengthened considerably (e.g., as evidenced by the increase in the average age of first marriage), and has become less standardized in terms of normative sequences of adulthood markers relating to work and marriage. These changes have led Arnett (1998, 2000) to argue that this period is more than simply a staging ground for adulthood, and that it should be viewed as unique and important in its own right. Others highlight that this major life transition shares important similarities with other significant life transitions, and therefore, should be viewed in that context to allow for the understanding of continuities and discontinuities across the life course (e.g., Schulenberg et al., 2003). It is noteworthy that the increased flexibility and self-direction that has become more apparent during this transi- 
tion mirrors what has occurred more generally across the life course in the past century (Heinz, 2002).

At the broader societal level in the United States, there is what Hurrelmann (1990) has called a "profound lack of institutional structure to facilitate the transition to young adulthood" (p. 236). In comparing the transition into adolescence with the transition into adulthood, it becomes evident that there is far less institutionally and culturally imposed structure on young people as they make the latter transition than as they make the former transition. On the positive side, this relative lack of structure can allow for greater self selection of paths and activities. In particular, this greater capacity for self-selection of contexts and roles after high school is likely one reason for the increase in well-being that occurs at the population level during this transition (Schulenberg et al., in press). However, for some young people, the relatively sudden drop in institutional structure can be debilitating, creating a mismatch between individual needs and contextual affordances. This discrepancy can result in avoidance of life tasks during this time (Mortimer, Zimmer-Gembeck, Holmes, \& Shanahan, 2002), creating a sense of floundering that can adversely affect mental health.

Like all major life transitions, the transition to adulthood is embedded in a sociocultural context, and therefore, may vary in occurrence, content, and meaning by gender, socioeconomic background, culture, and historical period. Culturally based, age-related expectations shape these transitions by providing a normative timetable and agenda (Neugarten, 1979). As a global life transition, the transition from adolescence to adulthood includes numerous specific developmental transitions that can be viewed as internally (e.g., biological, physical, cognitive, emotional, and identity related), as well as externally, based (e.g., changes in social roles and contexts; Rutter, 1996). Specifically, embedded within this global transition is a series of changes involving perspective taking, emotional regulation, identity, independence, affiliation (e.g., transitions in parental, peer, and romantic involvements) and achievement (e.g., transitions from school to work; Schulenberg et al., 2003). In addition, there are normal neurobiological changes that take place during the transition from adolescence to early adulthood, including synaptic pruning of the prefrontal cortex, developmental transformations in prefrontal cortex and limbic brain regions, and continued myelination of intracortical and mesolimbic dopamine systems (Benes, 1989; Keshavan \& Hogarty, 1999; McGlashan \& Hoffman, 2000; Spear, 2000; Thompson \& Nelson, 2001; Yakovlev \& LeCours, 1967). As Cicchetti and Tucker (1994) have explicated, such an interaction among these various changing developmental domains and contexts must also take into account the individual's active strivings for self-organization that critically affect brain development and gene expression.

Closely aligned to these transitions are developmental tasks. The distinction between the two is that transitions pertain more to the process of change, and tasks pertain more to accomplishments that contribute to, and result from, the changes (Elder, 1998; Schulenberg et al., 2003). Together, developmental transitions and tasks constitute the primary components of the shift or move to adulthood. Although there is not a single normative or prescribed pathway through these various tasks and transitions (Cohen et al., 2003; Settersten, 2003; Shanahan, 2000), successfully negotiating at least some of them (and particularly those viewed as central by the young person) is likely to be associated with more salutary trajectories of mental health well-being and to provide a foundation for optimal development during adulthood (Masten \& Curtis, 2000; Schulenberg \& Maggs, 2002; Wiese, Freund, \& Baltes, 2000).

\section{Conceptual Issues Related to Developmental Transitions}

An emphasis on developmental transitions highlights both developmentally proximal and distal influences on behavior, setting the foundation for considerations of turning points and developmental discontinuity (Elder, 1998; Rutter, 1996; Schulenberg et al., 2003). Furthermore, following from the emphasis on person-context interactions, considerations of 
individual similarities and differences in intraindividual change are essential, requiring less emphasis on normative trends in developmental change and more emphasis on different trajectories of change over time. More generally, curiosity about so called nonnormative cases and situations is enriching for our theories and research efforts (Cicchetti \& Rogosch, 2002).

\section{Discontinuity and continuity}

Issues of continuity and discontinuity are central to understanding the power of major developmental transitions on individuals' lives (Cicchetti \& Schneider-Rosen, 1986; Rutter, 1996; Schulenberg et al., 2003; Sroufe \& Jacobvitz, 1989). Statistically, continuity and discontinuity are sometimes considered in terms of stability and operationally defined by the strength of autocorrelations across time. But developmentally, discontinuity is considered more complex in terms of turning points in personal trajectories. Although apparent discontinuities in functioning across transitions may reflect momentary disturbances, after which one's ongoing trajectory will resume, representing a continuity of general adaptative capacities, major transitions like the one from home to college can permanently alter one's ongoing trajectory of health and wellbeing. For example, although the majority of young people mature out of their substance use as adulthood begins (Bachman, O'Malley, Schulenberg, Johnston, Bryant, \& Merline, 2002), some continue into adulthood with increasing substance use and related problems. Differentiating these similar two groups prior to the transition is difficult, because separating the normative social drinking expectations of late adolescence from personal susceptibilities is difficult to do at the behavioral level (e.g., Jackson, Sher, Gotham, \& Wood, 2001; Windle \& Davies, 1999), suggesting that the transition itself may impact the continuation of substance use-related problems into adulthood (Schulenberg \& Maggs, 2002).

These issues have implications for the application of concepts of equifinality and multifinality to an understanding of developmental periods (Cicchetti \& Rogosch, 1996b). For ex- ample, if one were studying adolescence with problem behavior as the endpoint of concern, then equifinality would be implicated because the vast majority of problem youth engage in some form of delinquency (Elliott, Huizinga, $\&$ Ageton, 1985). Because of the lack of variance in adolescent engagement in problem behaviors broadly defined, childhood predictors would all lead to the same equifinal outcome. However, if adulthood were the endpoint of concern, then multifinality would be implicated because adolescents with the same levels of problem behavior may have completely different outcomes. In this light, there may be better predictions from more temporally distant problem behaviors in childhood to adulthood antisocial behavior than from more proximal adolescent delinquency, implicating an underlying continuity in individuals that is masked by cultural norms. This is the basis for Moffitt's (1993) distinction between adolescent limited and life-course persistent antisocial behavior.

\section{Distal and proximal developmental influences}

Closely tied to these issues of continuity and discontinuity is the relation between temporally distal and proximal influences. Developmental transitions reflect proximal developmental influences, which are often intertwined with more distal influences. With regard to adulthood functioning, distal childhood influences (e.g., ongoing parental discord and substance abuse) may set the stage for proximal influences (e.g., lack of parental monitoring and support during late adolescence, high susceptibility to peer pressure to abuse substances); alternatively, proximal influences may mediate the effects of distal influences (e.g., childhood events contribute to adulthood dysfunction via difficulties with the transition to adulthood). However, proximal developmental influences in general, and developmental transitions in particular, may operate independently of distal influences or may even disrupt distal influences, thus setting the stage for discontinuity. The transition to marriage, for example, often serves to block or reverse earlier influences with respect to anti- 
sociality, psychopathology, and substance abuse (Bachman et al., 2002; Laub \& Sampson, 1993; Rutter, 1996).

\section{Key Themes in This Special Issue}

Although there are many aspects to the transition to adulthood, for this Special Issue we have delimited our concerns to areas directly relevant to developmental psychopathology. These include several conceptual and methodological themes related to continuity and discontinuity in person-context interactions, distal and proximal influences, individual differences and similarities in intraindividual change, and the unique nature of the transition to adulthood, all of which represent foundations for understanding psychopathology and mental health across the life course.

\section{Development and psychopathology}

A major concern in our field is to separate features of development and psychopathology, especially as they relate to the definition of what is maladaptive. Nondevelopmental perspectives assume that the definition and specific elements of mental health are continuous across the life span. However, this assumption needs to be examined for each developmental period, and for our purposes here, specifically with respect to the transition to adulthood. Behaviors that in one context are considered deviant, in another may be age-appropriate. For example, during this transition, substance use that is usually considered destructive can serve constructive purposes as well in terms of contemporary social bonding and quests for independence from earlier family and community constraints (Schulenberg \& Maggs, 2002). Similarly, depression may reflect difficulties in the active engagement with the new contexts of early adulthood in a continuation of identity formation, perhaps serving as a mechanism for self-examination and self-change. Although not all deviances and difficulties can be viewed as functional rather than as maladaptations reflecting pathology, raising the issue of defining behavior in context should increase our ability to understanding the po- tentially unique aspects of emerging adulthood (Schulenberg \& Zarrett, in press).

The articles in this Special Issue focus on both psychopathology and mental health aspects of adult outcomes. The disorder for many articles is externalizing behavior, defined as either aggression, antisocial behavior, conduct problems, or delinquency. Internalizing behaviors also are represented, with several articles focused on depression and some on anxiety. Substance use and abuse is another major theme, with a number of articles about transitions in alcohol and drug utilization. On the positive side are studies with personal characteristics of self-esteem and well-being as outcomes, or more interactional constructs of mastery of stressful life events or coping with stress.

\section{Continuity and discontinuity in person-context interactions}

Although it is clear that there are strong continuities in psychopathology and mental health across the life span, it is important to understand when and where discontinuities occur. "When" in this case is during the transition to adulthood. "Where" can be in the individual, the personal contexts of family, peer groups, and community, or the larger political settings that determine the availability of resources for the personal settings.

From a person-context interaction perspective, where mental health relates to adaptation and mutual accommodation of individual and context (Sameroff, 2000), there are likely to be discontinuities in psychopathology and mental health during this major life transition. The new contexts and social roles of early adulthood can create increased or decreased matches between individual needs and contextual affordances. Thus, old difficulties may fade away and new ones may emerge. Although some of the emerging difficulties are predictable in advance based on earlier characteristics or life experiences, others may surface directly as a result of both positive and negative experiences during the transition to adulthood, highlighting the power of major life transitions as turning points. 
Experiences examined in this Special Issue range across the many developmental contexts relevant to the transition to adulthood. The family is considered, and there is much interest in the effects of peer, neighborhood, and employment characteristics in influencing adaptation across the transition. The articles offer a range of comprehensiveness in this regard, with some focusing on single contexts and others assessing the relative importance of, for example, family, peer, school, and neighborhoods.

\section{Uniformity and multiformity of development}

An important crosscutting theme in this Special Issue involves the juxtaposition of variablecentered and person- or pattern-centered approaches illustrated in the various articles. Whereas variable-centered approaches seek central tendencies that characterize modal developmental progress, person-centered approaches look for subgroups with unique pathways through developmental periods (Cicchetti \& Rogosch, 1996a; von Eye \& Bergman, 2003). Both approaches have their advantages and disadvantages as represented by the articles in this Special Issue. The ultimate aim is the understanding of patterns of adaptive and maladaptive behavior across the life span, and the judgment of which approach is more useful will depend on the success of each in helping us to approximate this goal.

A variety of person-centered approaches are represented in this Special Issue. Empirical and a priori methodologies are used to identify groups that show continuity or change across the transition. These range from the modal four continuous, high-high and low-low, and discontinuous, high-low and low-high, problem groups to quadratic variations requiring seven groups with specifiably different trajectories.

\section{Proximal and distal temporal influences}

One of the important questions related to explaining behavior at any point in time is the extent to which it is a function of prior individual characteristics and experiences or wholly related to current circumstance. The focus in this Special Issue on developmental studies that offer the possibility of answering this question is an important contribution. The following articles offer a number of strategies for estimating the relative influence of prior versus current factors, and report a number of different results for different outcomes and different individuals. For some outcomes, current experiences explain more of the variance, whereas for others prior situations have continuing influences. For some groups, either in the trajectory analyses or in comparison of males and females, the relative significance of prior and contemporary experiences varies as well. The picture that emerges can be interpreted as overly complex because of the many different combinations of individuals, experiences, and outcomes, or as richly multifaceted, illuminating the many adaptive and maladaptive paths from childhood and adolescence into adulthood (cf. Sameroff \& MacKenzie, 2003).

\section{Uniqueness of the transition to adulthood}

What makes this major transition unique is the potential for extensive changes in nearly all aspects of life within a few short years, coupled with great heterogeneity in life paths. These qualities are well represented in the articles in this Special Issue. Much of the early research on this transition focused on variation in trajectories as a function of college versus work pathways, and how gender served to direct much of the experience of this transition. Currently, although the emphasis on work and college trajectories and gender and other subgroup variations is still evident and reflects important themes, emphasis has increased around issues related to achieving and not achieving developmental tasks and the path to individual identity. An important theme here is how the tasks and transitions can contribute to a consolidation of psychopathology and mental health. A related theme is the extent to which this transition is a "hanging out" time. From a societal and individual level perspective, perhaps some floundering during this transition may be important and adaptive for identity development.

In conclusion, we believe that the contributions to this Special Issue will advance our 
knowledge about how the adolescence to adulthood transition relates to the course of psychopathology and mental health. This Special Issue is particularly critical because it highlights the lifespan perspective embodied by the field of developmental psychopathology (Cicchetti, 1993; Zigler \& Glick, 1986). A developmental understanding of adaptation is not limited to childhood, but cuts across all periods of the life course. Although many important questions and issues remain to be addressed, it is our hope that the papers in this issue collectively will spark future thinking, research, and intervention on this largely understudied, but clearly important, transition.

\section{References}

Arnett, J. J. (1998). Learning to stand alone: The contemporary American transition to adulthood in cultural and historical context. Human Development, 41, 295-315.

Arnett, J. J. (2000). Emerging adulthood: A theory of development from late teens through the twenties. American Psychologist, 55, 469-480.

Bachman, J. G., O’Malley, P. M., Schulenberg, J. E., Johnston, L. D., Bryant, A. L., \& Merline, A. C. (2002). The decline of substance use in young adulthood: Changes in social activities, roles, and beliefs. Mahwah, NJ: Erlbaum.

Benes, F. M. (1989). Myelination of cortical-hippocampal relays during late adolescence: Anatomical correlates to the onset of schizophrenia. Schizophrenia Bulletin, $15,585-594$.

Cairns, R. B. (2000). Developmental science: Three audacious implications. In L. R. Bergman, R. B. Cairns, L. G. Nilsson, \& L. Nystedt (Eds.), Developmental science and the holistic approach (pp. 49-62). Mahwah, NJ: Erlbaum.

Cicchetti, D. (1993). Developmental psychopathology: Reactions, reflections, projections. Developmental $R e$ view, 13, 471-502.

Cicchetti, D., \& Rogosch, F. A. (Eds.). (1996a). Developmental pathways: Diversity in process and outcome [Special Issue]. Development and Psychopathology, 8, 597-896.

Cicchetti, D., \& Rogosch, F. A. (1996b). Equifinality and multifinality in developmental psychopathology. Development and Psychopathology, 8, 597-600.

Cicchetti, D., \& Rogosch, F. A. (2002). A developmental psychopathology perspective on adolescence. Journal of Consulting and Clinical Psychology, 70, 6-20.

Cicchetti, D., \& Schneider-Rosen, K. (1986). An organizational approach to childhood depression. In M. Rutter, C. Izard, \& P. Read (Eds.), Depression in young people, clinical and developmental perspectives ( $\mathrm{pp}$. 71-134). New York: Guilford Press.

Cicchetti, D., \& Tucker, D. (1994). Development and selfregulatory structures of the mind. Development and Psychopathology, 6, 533-549.

Cohen, P., Kasen, S., Chen, H., Hartmark, C., \& Gordon, K. (2003). Variations in patterns of developmental transitions in the emerging adulthood period. Developmental Psychology, 39, 657-669.

Curtis, W. J., \& Cicchetti, D. (2003). Moving research on resilience into the 21 st century: Theoretical and methodological considerations in examining the biological contributors to resilience. Development and Psychopathology, 15, 773-810.

Elder, G. H. (1998). The life course and human develop- ment. In W. Damon \& R. M. Lerner (Eds.), Handbook of child psychology: Theoretical models of human development (Vol. 1, pp. 939-991). New York: Wiley.

Elliot, D. S., Huizinga, D., \& Ageton, S. (1985). Explaining delinquent behavior and drug use. Beverly Hills, CA: Sage.

Heinz, W. (2002). Self-socialization and post-traditional society. In R. Settersten \& T. Owens (Eds.), New frontiers in socialization (pp. 41-64). New York: Elsevier.

Hurrelmann, K. (1990). Health promotion for adolescents: Preventive and corrective strategies against problem behavior. Journal of Adolescence, 13, 231-250.

Jackson, K. M., Sher, K. J., Gotham, H. J., \& Wood, P. K. (2001). Transitioning into and out of large-effect drinking in young adulthood. Journal of Abnormal Psychology, 110, 378-391.

Keshavan, M. S., \& Hogarty, G. E. (1999). Brain maturational processes and delayed onset in schizophrenia. Development and Psychopathology, 11, 525-544.

Laub, J. H., \& Sampson, R. J. (1993). Turning points in the life course: Why change matters to the study of crime. Criminology, 31, 301-325.

Lewis, M. (1999). Contextualism and the issue of continuity. Infant Behavior and Development, 22, 431-444.

Masten, A. S., \& Curtis, W. J. (2000). Integrating competence and psychopathology: Pathways toward a comprehensive science of adaptation in development. Development and Psychopathology, 12, 529-550.

McGlashan, T. H., \& Hoffman, R. E. (2000). Schizophrenia as a disorder of developmentally reduced synaptic connectivity. Archives of General Psychiatry, 57, 637-648.

Moffitt, T. E. (1993). Adolescence-limited and life-coursepersistent anti-social behavior: A developmental taxonomy. Psychological Review, 100, 674-701.

Mortimer, J. T., Zimmer-Gembeck, M. J., Holmes, M., \& Shanahan, M. J. (2002). The process of occupational decision making: Patterns during the transition to adulthood. Journal of Vocational Behavior, 61, 439-465.

Neugarten, B. L. (1979). Time, age, and the life cycle. American Journal of Psychiatry, 136, 870-894.

Rutter, M. (1996). Transitions and turning points in developmental psychopathology: As applied to the age span between childhood and mid-adulthood. International Journal of Behavioral Development, 19, 603-626.

Sameroff, A. J. (2000). Developmental systems and psychopathology. Development and Psychopathology, 12, 297-312.

Sameroff, A. J., \& MacKenzie, M. J. (2003). Research strategies for capturing transactional models of devel- 
opment: The limits of the possible. Development and Psychopathology, 15, 613-640.

Schulenberg, J. E., \& Maggs, J. L. (2002). A developmental perspective on alcohol use and heavy drinking during adolescence and the transition to young adulthood. Journal of Studies on Alcohol, 14(Suppl), 54-70.

Schulenberg, J. E., Maggs, J. L., \& O’Malley, P. M. (2003). How and why the understanding of developmental continuity and discontinuity is important: The sample case of long-term consequences of adolescent substance use. In J. T. Mortimer \& M. J. Shanahan (Eds.), Handbook of the life course (pp. 413-436). New York: Plenum Press.

Schulenberg, J. E., O’Malley, P. M., Bachman, J. G., \& Johnston, L. D. (in press). Early adult transitions and their relation to well-being and substance use. In F. Furstenberg, R. Rumbaut, \& R. Settersten (Eds.), On the frontier of adulthood. Chicago: University of Chicago Press.

Schulenberg, J. E., \& Zarrett, N. R. (in press). Mental health during emerging adulthood: Continuities and discontinuities in course, content, and meaning. In J.J. Arnett \& J. Tanner (Eds.), Advances in emerging adulthood. Washington, DC: American Psychological Association.

Settersten, R. A. (2003). Invitation to the life course: Toward new understandings of later life. Amityville, NY: Baywood Publishing Co., Inc.

Shanahan, M. J. (2000). Pathways to adulthood in changing societies: Variability and mechanisms in life course perspective. Annual Review of Sociology, 26, 667-692.

Sherrod, L. R., Haggerty, R. J., \& Featherman, D. L. (1993). Introduction: Late adolescence and the transition to adulthood. Journal of Research on Adolescence, 3, 217-226.

Spear, L. P. (2000). The adolescent brain and age-related behavioral manifestations. Neuroscience and Biobehavioral Reviews, 24, 417-463.
Sroufe, L. A. (1997). Psychopathology as an outcome of development. Development and Psychopathology, 9, 251-268.

Sroufe, L. A., Carlson, E. A., Levy, A. K., \& Egeland, B. (1999). Implications of attachment theory for developmental psychopathology. Development and Psychopathology, 11, 1-13.

Sroufe, L. A., Egeland, B., \& Kreutzer, T. (1990). The fate of early experience following developmental change: Longitudinal approaches to individual adaptation in childhood. Child Development, 61, 13631373.

Sroufe, L. A., \& Jacobvitz, D. (1989). Diverging pathways, developmental transformations, multiple etiologies, and the problem of continuity in development. Human Development, 32, 196-203.

Thompson, R. A., \& Nelson, C. A. (2001). Developmental science and the media: Early brain development. American Psychologist, 56, 5-15.

von Eye, A., \& Bergman, L. R. (2003). Research strategies in developmental psychopathology: Dimensional identity and the person-oriented approach. Development and Psychopathology, 15, 553-580.

Wiese, B. S., Freund, A. M., \& Baltes, P. B. (2000). Selection, optimization and compensation: An actionrelated approach to work and partnership. Journal of Vocational Behavior, 57, 273-300.

Windle, M., \& Davies, P. T. (1999). Developmental theory and research. In K. E. Leonard \& H. T. Blane (Eds.), Psychological theories of drinking and alcoholism (2nd ed., pp. 164-202). New York: Guilford Press.

Yakovlev, P. I., \& LeCours, A. R. (1967). The myelogentic cycles of regional maturation of the brain. In A. Minkowski (Ed.), Regional development of the brain in early life (pp. 3-64). New York: Oxford University Press.

Zigler, E., \& Glick, M. (1986). A developmental approach to adult psychopathology. New York: Wiley. 